\title{
A Qualificação/Requalificação do Engenheiro do Setor Metal-Mecânico
}

\author{
João Bosco Laudares \\ Doutor em educação pela PUC/SP e professor dos cursos de engenharia da PUC/MG e do Mestrado em Tecnologia do \\ CEFET/MG \\ Endereço: Rua Jornalista Moacir Andrade, 192 \\ $C E P$ - 30350410; Belo Horizontel $M G$ \\ Telefax: (31)3444163 -E-mail: paulal@bis.com.br
}

Resumo

Os novos processos de trabalho bem como o progresso técnico estão a requerer um engenheiro com qualificação de novo tipo. A formaçāo escolar e a capacitaçāo profissional não mais se restringem aos cursos formais acadêmicos, mas exigem uma educação continuada a partir da prática do trabalho e a volta à Escola.

Palavras-chave: qualificação, engenheiro, trabalho, educação, escola

\section{Abstract}

The new working process and the technological improvements demand an engineer with new qualifications. The academic background and the professional capability are not restricted to the conventional academic course, but they require a permanent education integrated to working practice.

Keywords: qualification, engineer, work, education, school

\section{Introdução}

As questões discutidas neste texto são originadas de uma pesquisa, realizada com engenheiros da fábrica montadora de automóveis da FIAT em Minas Gerais, da qual originou minha tese de doutoramento.

A literatura produzida pela Sociologia do Trabalho é profícua no estudo da qualificação e da educação da classe trabalhadora, do trabalhador do chão de fábrica. $\mathrm{O}$ objetivo das pesquisas e obras produzidas sobre esse segmento da classe trabalhadora tem sido analisar a adequação da força de trabalho às necessidades do setor produtivo, analisar a inserção social desses trabalhadores, bem como traçar seu perfil profissional diante das demandas do mundo do trabalho.

O desafio de sociólogos, educadores e profissionais de recursos humanos das empresas é o de entender quais são os parâmetros e as âncoras dos processos de mudanças que afetam o emprego, a qualificação para o trabalho e a educação tecnológica. De um modo geral, a identificação dos atributos qualificacionais do trabalhador é bipolarizada, uma vez que se deve considerar o binômio capital-trabalho: de um lado, o empresariado busca mecanismos que favoreçam o aumento da produtividade no trabalho, a qualidade do produto e, consequientemente, o acúmulo de ganhos, proporcionando, assim, uma participação crescente da empresa no mercado com maior competitividade; de outro, o trabalhador busca a promoção de sua capacitação, o desenvolvimento de suas habilidades e a ampliação de seu espaço profissional e social.

Em paralelo à mudança do paradigma de produção taylorista-fordista, assistimos a uma crise que provoca o desemprego estrutural, o surgimento de novas exigências de qualificação e, em certos setores das empresas, até mesmo uma reprofissionalização. Deste modo, no campo das Ciências Sociais e da Educação Tecnológica, é preciso 
PRODUÇÃO

efetuar uma análise crítica dos impactos das reestruturações produtivas sobre o perfil da força de trabalho. Trata-se de uma tentativa de dar respostas às transformações que ocorrem na organização do trabalho, na utilização das novas tecnologias da informática, da robótica e da microeletrônica e na performance do trabalhador.

A competência do trabalhador, que no modelo taylorista se definia simplesmente pelo conhecimento da execução de uma tarefa, passa agora, no cenário criado pela fábrica globalizada, a se estruturar através da aplicação de novos padrões produtivos. Isto requer a realização de multi-tarefas, o que provoca os seguintes questionamentos: com que desempenho de funções esses padrões produtivos estão mais relacionados? Quais são os atributos qualificacionais hoje requeridos?

A produção na área qualificacional para o trabalho direciona-se à integração da formação e do desempenho profissional, pois as transformações produtivas trazem a simultaneidade da educação e do trabalho, com ênfase na educação básica e geral seguida dos programas de educação continuada ou permanente, que são realizados em serviço, na própria empresa ou fora dela, por meio de intercâmbios com escolas.

No segundo plano da escala ocupacional da empresa, está o técnico com formação escolar média (segundo grau). No sistema taylorista da divisão de trabalho, este profissional situava-se na hierarquia funcional das empresas entre o engenheiro e o operário, e trabalhava em setores estratégicos da produção. Sua atuação, bastante efetiva, mostrava-se ora agregada ao escritório de projetos ora à produção, dependendo da organização, do tipo da empresa ou da formação do técnico. Ou seja, aquele técnico com formação mais teórica estaria ligado ao planejamento; o técnico com formação mais prática, à produção. Sua função de controle dos processos produtivos assemelhava-se à de um capataz (expressão utilizada por alguns autores como Lucília Regina de Souza Machado).

Com a introdução de novos padrões de gerenciamento e organização do trabalho, além da eliminação de chefias intermediárias e de seções da fábrica que eram dirigidas pelo técnico, torna-se necessário investigar como se posiciona e como atua esse profissional na produção. Temos, portanto, um amplo campo de pesquisa ainda com uma produção limitada, que demanda a realização de estudos. Isto é especialmente importante depois que o governo alterou a estrutura curricular dos cursos técnicos industriais, provocando uma separação rígida entre a educação profissional e a educação propedêutica. Assim, o ensino técnico será organizado independentemente do ensino médio, o que é contestado pelas Escolas Técnicas Industriais Federais, instituições que são modelos de formação técnica. A nova concepção pedagógica traz uma desintegração curricular, com a constituição modular do ensino, o que contraria os novos paradigmas das reestruturações produtivas assentadas na integração dos processos.

Há uma preocupação dos diversos segmentos responsáveis pela educação tecnológica em relação à implantação desse programa definido pelo Ministério da Educação. Os educadores atuantes nas escolas profissionalizantes temem que a educação técnica se transforme em treinamento profissional, sem a discussão de temas mais amplos relativos à inovação tecnológica, à produção industrial no país e à abordagem sócio-econômica no mundo do trabalho, em prejuízo da formação integral do técnico industrial desse nível.

Nos vários setores da empresa, encontramos um profissional de nível superior ocupando posições estratégicas - o engenheiro. A primeira questão a ser levantada é a seguinte: podemos enquadrar os engenheiros na classe trabalhadora, tendo em vista que para muitos estudiosos da Educação Tecnológica ou das Ciências Sociais este profissional é identificado como constituinte da classe empresarial, como seu legítimo representante? Essa situação é controversa, pois as consequêencias negativas dos atuais processos produtivos que provocam o desemprego, a intensificação do trabalho e a baixa remuneração, afetam sobremaneira os engenheiros. Desse modo, Vanilda Paiva (1995) denomina o engenheiro como proletário acadêmico, quando comparado a outros 
profissionais de nível superior, uma vez que também são afetados pelas conseqüências da restruturação produtiva. Já Kawamura (1981: 89), ao estudar a formação e o trabalho profissional do engenheiro, afirma que este profissional encontra-se em posição intelectual ambigua, pois ora é um dirigente, ocupando cargos superiores hierárquicos, ora é um trabalhador no desempenho técnico.

No Brasil há diminuta investigação na área de atuação e qualificação do engenheiro, sobretudo no que diz respeito à aplicação de diferentes modelos organizacionais e à utilização de novas tecnologias. Esperamos que os resultados da pesquisa realizada possam contribuir tanto para o estudo da educação tecnológica, no campo pedagógico, quanto para o estudo das qualificações, no campo da Sociologia do Trabalho. A escassa produção sobre essa área no Brasil acarreta dificuldades normais a um trabalho pioneiro. Há um amplo campo temático a ser explorado, o que pode ser facilmente observado se fizermos recortes no objeto de estudo. Por exemplo, é possível proceder uma investigação nos setores de engenharia de produção discreta ou de produção contínua; nestes dois segmentos podemos encontrar inúmeras áreas específicas até agora pouco investigadas. Ademais, podemos considerar os vários campos da engenharia como: construção civil, envolvendo questões ambientais; o setor químico, com a produção de novos materiais e com a exploração mineral; engenharia da computação e das telecomunicações, entre outros.

As hipóteses de trabalho, que norteavam a investigação, tratavam da necessidade de uma formação do engenheiro mais ampliada, fugindo do reducionismo de abrangência estritamente técnica, partindo do pressuposto que na educação tecnológica outras questões devem ser levantadas quanto à dimensão social, à econômica, à política da qualificação profissional.

A formação profissional requer uma contínua e permanente atualização, desconsiderando o curso formal acadêmico da Escola como terminal do processo educacional. A qualificação profissional deve ser entendida num movimento dinâmico de mutação da reestruturação produtiva, não só da tecnologia física de máquinas e equipamentos, mas, principalmente, organizacional, isto é, dos processos de gestão do trabalho.

A partir da constatação que o curso universitário não garante mais formação profissional perene, uma vez que as mudanças tecnológicas na sua natureza trazem necessidade de renovação formativas e qualificacionais para a polivalência profissional, as Escolas de Engenharia estão obrigadas a rever seus planos de curso, objetivos e metas curriculares. Questões fundamentais e precedentes à formatação da grade curricular dos cursos perpassam discussões, tais como: a graduação busca dar uma formação mais generalista ao futuro engenheiro? Se afirmativa, quais são as grandes linhas generalistas e sua abordagem. Como garantir dentro da abrangência generalista o estudo da tecnologia contemporânea, mutável e renovável rapidamente.

No discurso das temáticas dos cursos de engenharia, surge um elemento novo quanto à programação da educação continuada. Mas como implementá-la na relação Escola/Empresa? Ainda se busca parâmetros, pois vincular mundo do trabalho e mundo acadêmico não signfica tratá-las como variáveis de domínios já determinados. Há proposições de ambos os lados para definir os tipos de programas, sua concepção e operacionalização.

\section{2- A Estruturação da Pesquisa}

A estruturação da pesquisa quanto à trajetória qualificacional do engenheiro considerou três momentos que se articulam: (i) a educação formal acadêmica, como pré-requisito da qualificação; (ii) a consolidação da competência profissional, mediante a prática do trabalho; (iii) a educação continuada, propulsora dinâmica da requalificação da força do trabalho. A pesquisa constou de entrevistas semi-estruturadas, abordando os seguintes temas:

· avaliação do curso de Engenharia, quanto aos núcleos: formação básica, profissional e geral; 
PRODUÇÃO

- impactos do início do trabalho profissional, levando-se em consideração a formação acadêmica do engenheiro;

- qualificação necessária ao desenvolvimento do trabalho;

· requalificação demandada à atualização profissional do engenheiro;

- perspectivas de atuação profissional;

· pretensão de requalificação futura.

A estrutura deste texto é a mesma da pesquisa realizada, isto é, partindo da graduação, entendida como primeiro requisito da qualificação profissional, passando pela prática de trabalho e os programas da educação continuada. Três momentos constituintes de um sistema integrado para o processo de qualificação/requalificação do engenheiro.

\section{A formação acadêmica do engenheiro como pré-} requisito à sua qualificação.

Do profissional qualificado se requer o preenchimento de uma série de quesitos em termos cognitivos, de habilidades, articulação em contexto social, como a capacidade de negociar nas parcerias interempresas ou intersetoriais na produção, de se associar e atuar cooperativamente em times. A qualificação demanda essencialmente a capacidade de transferência, ou seja, uma capacidade de realizar a aplicação da teoria à prática concreta do trabalho. Este é o grande salto exigido do profissional qualificado com formação acadêmica superior. Teorizar o concreto, abstrair-se do real em direção ao campo imaginário na formulação das leis que regem os fenômenos. Isto revela a consistência da qualificação nos novos processos de trabalho, como exigência da tecnologia de base científica.

Ao problematizarmos a qualificação profissional do engenheiro a partir de sua formação acadêmica, admitimos, inicialmente, como um pré-requisito a aquisição do saber-acumulado na Universidade, mas de forma crítica,

dedutiva, com o desenvolvimento da capacidade de transferência - a geração do novo a partir do velho.

$\mathrm{O}$ engenheiro, ao trabalhar na fábrica global, atua de uma forma decisiva para a elaboração e a implementação dos sistemas fabris e para o desenvolvimento de novos produtos ou componentes. Esta ação diversificada e conceptiva exige competências para a aplicação e renovação do conhecimento. Dessa forma, podemos entender a formação acadêmica do engenheiro pela evolução da organização e gestão dos processos laborais, implementados nas empresas.

No taylorismo, a produção se realizava acumulativamente por estoque, em grandes séries, com padronização e uniformidade do produto. A inovação acontecia em grandes intervalos de tempo, sem atingir contínuas reengenharias. As mudanças eram realizadas em suaves saltos, nem tão longos nem muito significativos. A tecnologia gerada pela experimentação muitas vezes acontecia por justaposição, sem uma fundamentação teórica. Nesse espaço, a liderança da força de trabalho era dos detentores das técnicas imutáveis ao longo do tempo.

Destacava-se, então, o trabalhador denominado prático, cujo conteúdo das atividades não demandava o conhecimento dos parâmetros diretores da lógica tecnológica, nem da identificação e domínio das variáveis intervenientes da interação do conhecimento teórico com o saber-fazer. Sua competência era de trabalhar o concreto, o realizável; executar as tarefas repetidas, padronizadas, parcelares, operacionalizadas em postos fixos. No binômio teoria/prática, a prática suplantava a teoria, destacando-se a ação do chão de fábrica.

Enquanto no setor produtivo predominava a prática, nas escolas, segundo Kawamura (1981: 84), se desenvolvia uma educação tecnológica voltada ao academicismo, descolada da produção industrial, principalmente nas Escolas de Engenharia.

Ao iniciar sua vida profissional, o engenheiro entrava em conflito com essa situação, e somente 
após vários anos de trabalho conseguia responder às demandas em serviço, com produtividade.

Já no pós-taylorismo, acontecem mudanças estruturais com novos padrões de gestão laboral e de concepção produtiva, privilegiando a demanda do mercado e do cliente em contraposição à acumulação da produção por estoque; a fabricação se faz em séries restritas de produtos diferenciados, substituindo a padronização. Se o sistema taylorizado da produção em massa era contrário à variedade de modelos, com restritas mudanças nos processos de trabalho, os sistemas pós-taylorizados são mais flexíveis e sua plasticidade permite uma adaptação a situações diversas. Os processos produtivos pós-taylorizados, segundo Coriat (1992: 70-71), são estabelecidos com base nos seguintes critérios:

todos incluem o uso produtivo de uma ou várias séries de materiais novos de processamento da informação, pois não se tem definido critério de classificação em função da complexidade tecnológica da linha de produção; um grau de complexidade ou de sofisticação tecnológica evidenciando cada uma das formas examinadas combinando em seu interior inovações organizacionais e inovações tecnológicas; maior flexibilidade entendida como capacidade de diferenciar rapidamente os produtos fabricados; a engenharia produtiva integra as novas tecnologias no sentido dos conceitos clássicos taylorismo e fordismo de organização.

A metodologia laboral pós-taylorizada se revela pela concretização de sucessivas inovações, com utilização de tecnologia intensiva na nova base técnica da microeletrônica e da informatização computacional generalizada. A diversificação dos produtos se faz também com a incorporação de tecnologia embarcada. Há uma valorização tanto da engenharia de produção e engenharia de processo como da engenharia de produto. A fábrica se abre em rede. As exigências de qualificação não se reduzem ao conhecimento técnico voltado à fabricação. Uma nova gestão de produção aparece com postos polivalentes, autonomia para os times e a busca da desespecialização.
A passagem pela escola, quando da realização de um curso superior, é um dos itens que credencia o engenheiro para o exercício de sua função, para um desempenho técnico efetivo. Mas a grande dúvida é: qual a abrangência do conteúdo programático do ensino a ser ministrado nos cursos profissionais do ponto de vista social, da empresa, ou do próprio indivíduo, para seu crescimento pessoal e profissional? Como resolver a dicotomia entre o modelo do ensino especialista e o generalista?

A cultura técnica, o domínio das máquinas e dos mecanismos produtivos, por si só, não correspondem à totalidade da preparação do profissional. O alicerce da cultura técnica se enriquece ao ser contemplado por abordagens da economia, da sociologia, da administração, de modo que as questões possam ser tratadas com um enfoque sistêmico.

A formação acadêmica, pré-requisito da qualificação profissional, busca sua eficácia a partir de um olhar prospectivo do mundo do trabalho e das profissões. É preciso considerar a dimensão qualificacional do trabalho, devendo a escola garantir a introdução desta dimensão, implantando nos seus programas o método da educação pela pesquisa do conhecimento, como algo inacabado, mutável, com possibilidade de reconstrução e, sobretudo, de transferência.

\section{A consolidação da competência profissional,} mediante a prática do trabalho.

A literatura produzida no contexto da Sociologia do Trabalho e da Administração de Recursos Humanos, relativa à qualificação da força de trabalho, tem se voltado ao estudo dos novos atributos definidores do perfil profissional do trabalhador. Há um consenso quanto às mudanças significativas de competências. Além de escolarização, baseada em um bom currículo, de experiência e atualização técnica, outros atributos são agregados ao perfil qualificacional do trabalhador no que se refere à conduta comportamental ou de atitude. Tais atributos são: capacidade de comunicação, de 
PRODUÇÃO

articular e de contextualizar informações; constante atualização; habilidade para compreender questões lógicas e solucionar conflitos; familiaridade com computadores e novas tecnologias; gosto pela pesquisa; responsabilidade; disciplina; capacidade de negociação.

A informação é a base do novo paradigma tecnológico. A tendência é de eliminação de fronteiras, que nos sistemas tradicionalistas tayloristas demarcavam rigidamente o planejamento (projeto) e a produção, segregando e setorizando a informação. O trabalho se faz mais na informação do que no objeto concreto. Cresce a importância da abstração na capacidade de ordenar e dar sentido a fluxos de dados e informações. A matéria-prima é a informação. Ganhará qualificação quem souber buscála com o domínio das técnicas de informática; quem conseguir processá-la; quem fizer sua interação com a visão totalizante dos processos.

$\mathrm{Na}$ economia globalizada e com a aplicação do sistema interfirmas analisado por Coriat (1994:130),

sobressaem as dimensões do saber-fazer-relacional e saber-fazer-técnico organizacional.

O desempenho profissional, nos sistemas organizativos da globalização, estão a solicitar não apenas a realização técnica, mas a competência para trabalhar a informação por meio dos sistemas inovativos de organização e de gestão. Com isto, há uma renovação nos atributos qualificacionais, pois quando se trata do setor produtivo, perdem lugar os operadores de máquinas de ferramentas convencionais, os operários artífices, os técnicos de controle de serviços e os supervisores de chefias intermediárias (o trabalhador do chão de fábrica e o técnico com formação acadêmica de nível médio). Por outro lado, ganham espaço os trabalhadores das atividades de serviços em geral, da interação dos mercados, do desenvolvimento de produtos e processos e da engenharia de sistemas (os engenheiros). Nestes novos processos o trabalhador necessita da flexibilidade na variedade de funções; necessita saber integrar-se a diferentes formas de mobilização de trabalhos.

Neste contexto de uma produção integrada e flexível, o trabalho em equipe assegura uma participação regulada, ao diminuir a importância dos postos fixos e das tarefas parciais. Ademais, com a eliminação de postos de trabalho, na integração da produção, assistimos ao aparecimento de um novo quadro de profissões. No Brasil, a classificação dos cargos ou funções nos processos produtivos é ampla. Resumidamente, podemos distinguir os seguintes níveis: operário semi-especializado, operário especializado, técnico (nível médio de escolaridade), engenheiro (graduado ou pós-graduado).

$\mathrm{O}$ engenheiro, profissional de nível superior exerce uma atividade basicamente intelectual, ou seja, entre suas atividades não predominam as funções operativas e seu campo de trabalho está em contínua metamorfose. Alteram-se as estruturas hierárquicas verticalizadas, que cedem lugar a uma maior integração horizontal; nessa nova estruturação, o engenheiro ganha maior espaço para atuar.

Em síntese, além da formação técnica, constatamos na nossa pesquisa que outros conhecimentos balizam a performance profissional do engenheiro, como o domínio dos conteúdos relativos à gestão, aos negócios, ao direito, à tecnologia de informação e das línguas estrangeiras.

\section{A educação continuada propulsora dinâmica da} requalificação da força de trabalho.

No caso do engenheiro, a escola oferece, na graduação, apenas uma introdução à profisssionalização. Assim, a questão é como a educação continuada irá complementar e concretizar essa tarefa, com a estruturação de um processo não limitado e que garanta a continuidade dos programas qualificacionais introduzidos pela escola. A contínua expansão do sistema educativo exige estratégias, atingindo o sistema produtivo e avançando na prática do trabalho, que também tem uma dimensão qualificacional.

A instituição de ensino superior tem sua missão assentada no tripé ensino, pesquisa e extensão. Destas três finalidades a extensão é aquela de mais difícil estruturação porque é uma ação informal, contratual, de 
administração compartilhada: uma ação entre escola e outra instituição. As atividades de extensão podem ser de caráter cultural, social, de prestação de serviço e de apoio às ações da formação profissional. A escola estabelece uma parceria com o setor produtivo para prestar consultoria técnica, para desenvolvimento de projetos ou para treinamento e educação profissional dos trabalhadores. Entretanto, o setor educacional ainda não está estruturado para exercer com plenitude ações de extensão. Não há ainda um planejamento formal desta articulação educação-trabalho. A administração acadêmica das escolas de engenharia preocupa-se quase que exclusivamente com a programação curricular. A missão ensino, pesquisa, extensão se resume apenas à administração intramuros. Algumas escolas, para iniciar uma relação com o mundo do trabalho, criam um setor específico voltado aos programas de extensão, denominado Instituto de Educação Continuada-IEC. Por intermédio deste órgão escola e empresa podem interagir e criar os laços de integração.

A extensão universitária complementa a formação acadêmica, o ensino formal, e busca dar apoio à pesquisa. É preciso entender que a ação de pesquisar não se refere necessariamente à descoberta de ponta, de processos e mecanismos sofisticados e de última geração, apoiados por tecnologias com base em inovações científicas. A pesquisa de graduação é realizada por equipes constituídas de acadêmicos e profissionais das empresas. Tem o objetivo de resolver problemas ou buscar soluções para questões levantadas na produção as quais necessitam de reflexão, sem paralisar os processos produtivos. Não se trata de grandes descobertas, o que ocorre nos institutos especializados de pesquisas. Nestes trabalhos, são realizadas tarefas diversificadas: treinamentos e mini cursos, visitas técnicas, trocas de experiências técnicas, aprendizagem de convivência em equipes, entre outras. A pesquisa tecnológica fomenta os programas de extensão e ambos provocam a demanda de qualificação profissional.

\section{3- Operacionalização do Trabalho de Campo}

\section{A fábrica global}

A primeira preocupação ao iniciar a pesquisa foi conhecer o campo de atuação dos engenheiros. Para determinar o número e o tipo de profissional a ser entrevistado, contemplamos todas as áreas da Empresa. As entrevistas foram realizadas em duas etapas: antes e após o Exame de Qualificação. Esta estratégia foi utilizada com o objetivo de aprofundar as questões levantadas e debatidas naquele momento. Além da montadora de carros, foram visitadas duas empresas fornecedoras da montadora devido à constituição da FIAT, como fábrica global, caracterizada pela total abertura e captação de processos, de mecanismos, de instrumentação e de componentes, independente de distâncias. A terceirização é uma realidade incontestável na fábrica globalizada.

$\mathrm{Na}$ década de 80 , os profissionais em tecnologia preconizaram a fábrica do futuro, na qual ocorreria a aplicação das inovações tecnológicas, com a informatização computadorizada e os complexos comandos automatizados; seria uma fábrica de máquinas, com o mínimo de trabalhadores e a substituição dos meios de produção da base técnica eletromecânica pela microeletrônica. Esperava-se que, na década de 90, a automação flexível integrada por computadores para controle da fabricação fosse um padrão dominante. A robótica seria irreversível, além do avanço tecnológico e do computador com algum grau de inteligência artificial. Entretanto, não é o que está ocorrendo. A difusão da automação se dá de forma seletiva e aplicada a setores específicos, como nas fábricas montadoras de carros: nas operações de solda, em parte da seção de pintura e de deslocamento do produto em transformação. A implantação destes mecanismos automatizados ocorre em ritmo cauteloso e bastante seletivo, o que constatamos na nossa investigação.

Por outro lado, uma outra fábrica chegou com tendência a permanecer: a fábrica globalizada, resultante do 
PRODUÇÃO

processo da globalização da economia. O processo de internacionalização do capital, através da integração mundial, não integra nações nem sistemas econômicos nacionais, mas conjuga ações dos grandes grupos entre si e no interior deles. A terceirização é uma realidade incontestável, com a engenharia de produto e desenvolvimento. As compras são realizadas no mercado global, independentemente da região ou da distância.

\section{As mudanças da organização do trabalho e da} gestão na empresa.

A empresa pesquisada promoveu alterações significativas na sua organização do trabalho e na gestão empresarial. Objetiva ganhar em produtividade, além da mais-valia relativa extra oriunda da competição inter empresas. Constatamos três etapas de mudanças dos processos de trabalho, bem definidos:

- divisão tradicional do trabalho nos moldes taylorista/fordista;

· implantação do PQT - Programa de Qualidade Total;

· evolução do Plano de Qualidade Total com adoção da Fábrica Racionalizada ou Empresa Enxuta, e a implantação das famílias/plataformas de produtos.

No primeiro momento, que corresponde ao período dos dez primeiros anos de implantação da Empresa no Brasil, prevaleceu a organização do trabalho segmentada com forte divisão de tarefas. A fabricação, no Brasil, do modelo de carro com defasagem tecnológica em relação aos modelos europeus não criou uma demanda de empreendimentos significativos, colocando o mercado brasileiro em posição desconfortável.

No final da década de 80, a Fiat lançou produtos tecnologicamente mais sofisticados, o que acarretou um crescimento do volume da produção do mercado brasileiro, que passou de $8 \%$ para $27 \%$, (dados fornecidos pelo setor comercial da Empresa) ou seja, quase um terço do mercado. Como conseqüência, houve necessidade de otimizar o trabalho na fábrica, ocorrendo a implantação do Plano de Qualidade Total -PQT.

Com a implantação do PQT, houve mudança nos processos de trabalho, pois o centro de atenção não era apenas a melhoria da fabricação, mas o atendimento das demandas do cliente. Todos os objetivos da Empresa convergiam para a satisfação do cliente. A qualidade foi tomada como uma filosofia global e os trabalhadores de todos os níveis, chamados colaboradores, pensavam e procuravam a excelência de produtos e serviços, através do atendimento perfeito oferecido ao cliente, de forma confiável, acessível, segura e no tempo certo. O plano de qualidade total foi ancorado em três princípios:

· foco no cliente;
·trabalho em time;
· administração por processos.

Esse plano exigiu qualificação de pessoal e, para a Empresa, havia a necessidade do comprometimento pessoal de todos os trabalhadores, além do constante desenvolvimento profissional. Isto definiria o nível de qualidade na produção, acarretando uma melhor condição de competição da Empresa no mercado, otimizando serviços e processos.

Já o modelo da Fábrica Racionalizada ou Enxuta trouxe uma mudança radical (característica da reengenharia da FIAT), em função da nova estrutura organizacional e diferente cultura empresarial. A reestruturação dos processos de trabalho se fez com a introdução da Unidade Tecnológica Elementar - UTE e do trabalho por famílias de produtos, desenvolvidos em plataformas (formas organizacionais para fabricação de produtos derivados de uma mesma linha). Essa reestruturação também envolveu uma redução de hierarquias com a eliminação de níveis intermediários, tais como chefe de seção e contramestres; foi adotada a administração horizontalizada com a finalidade de desenvolver a co-gestão dos processos, ou seja, substituiu- 
se a gestão por tarefa pela utilização da administração por processo, objetivando pensar e trabalhar, isto é, dar oportunidade ao trabalhador de participar das decisões relativas a sua ação.

A participação dos engenheiros da Empresa nesses três momentos distintos (taylorismo, PQT e fábrica racionalizada), fez-se em várias etapas. Como o planejamento de todos os novos sistemas foi realizado em grande parte pelo pessoal da própria Empresa, os engenheiros foram envolvidos como todos os trabalhadores e, na execução, tomaram parte ativa. Realizaram cursos e fizeram treinamentos, principalmente para a implantação da Fábrica Enxuta e Racionalizada, que mudou as estruturas com um achatamento hierárquico e com a criação de grupos interfuncionais. Isto ampliou a base da pirâmide organizacional da Empresa, de modo que foi necessário capacitar profissionais para os novos processos.

Apesar da redução de postos hierárquicos ocupados pelos engenheiros, estes não saíram da cadeia produtiva ou reduziram suas funções, pois ganharam novos postos na base piramidal organizacional da empresa. O engenheiro é um catalizador e disseminador do conhecimento tecnológico, assim, seu envolvimento no processo resulta em crescimento técnico e cultural de toda base.

Ao ser questionado sobre a atuação do engenheiro nos novos processos e se seu campo de trabalho seria reduzido com o encurtamento de hierarquia, um dos gerentes declarou:

O engenheiro não sai do processo porque fica ampliado seu campo de ação também na base, não só no topo da pirâmide, o que antes ocorria, quando os engenheiros eram somente gerentes. Hoje, com a evolução e a mudança tecnológica acelerada há necessidade de profissionais com maior bagagem para uma adaptação mais rápida, pois os profissionais sem graduação levavam mais tempo para uma ação efetiva. $O$ campo do engenheiro está, então, expandindo. À medida que as mudanças ocorrem velozmente há necessidade de profissionais com potencial para assimilar estas mudanças com velocidade maior e alterar conseqüen- temente os processos. Não há lugar para aquele profissional prático que detinha um conhecimento extremamente especifico e sozinho dominava o campo de trabalho por muitas anos. O conhecimento hoje é rapidamente renovável.

O engenheiro é um agente multiplicador e difusor de novos processos de trabalho, como profissional de ponta na empresa. Ao liderar o planejamento de produção e o setor industrial, exerce uma atividade intelectual, utilizando uma memória histórica e contextualizada em relação a problemas já vividos e resolvidos em situações anteriores. Ademais, exerce a capacidade de intervenção na análise crítica de questões, desenvolvendo a competência da transferência e aplicabilidade do conhecimento. $\mathrm{Na}$ prática do seu trabalho, garante o crescimento da inteligência da fábrica, ao realizar uma ação não apenas técnica, mas ligada à qualidade dos processos e do produto até à gestão da produção.

\section{4- Principais Constatações}

\section{A atuação diversificada do engenheiro na} empresa

A entrada na empresa aconteceu pela diretoria de relações industriais, cuja função é trabalhar os programas da qualificação profissional. A primeira informação adquirida e acompanhada de dados primários foi quanto ao campo de atuação dos engenheiros na empresa. Pudemos constatar, pela distribuição dos engenheiros, ocupando posições em todas as áreas da empresa, que a formação tecnicista do engenheiro não pode ser o único sustentáculo da sua qualificação profissional. Pois, os engenheiros não mais atuam concentrados e preferencialmente no setor estritamente industrial das empresas, confirmando nossa hipótese da sua capacitação mais generalista, não mais limitada ao saber-fazer técnico. Tomamos os dados em dois momentos ao iniciar a pesquisa (setembro de 96) e no final da mesma (fevereiro de 98). A distribuição dos engenheiros na empresa pesquisada estava conforme tabela a seguir. 


\begin{tabular}{|c|c|c|c|}
\hline ÁREA & $\begin{array}{l}1996 \\
\text { SETEMBRO }\end{array}$ & $\begin{array}{l}1998 \\
\text { FEVEREIRO }\end{array}$ & $\%$ \\
\hline ADMINISTRATIVA FINANCEIRA & 5 & 15 & 2,7 \\
\hline COMPRAS & 44 & 78 & 14,1 \\
\hline PESSOAL E ORGANIZAÇÃO & 20 & 24 & 4,4 \\
\hline LOGÍSTICA & 5 & 8 & 1,5 \\
\hline COMUNICAÇÃO SOCIAL & 1 & 10 & 0,1 \\
\hline PRODUTO & 6 & 15 & 2,7 \\
\hline ENGENHARIA PRODUTO & 64 & 115 & 20,9 \\
\hline COMERCIAL & 82 & 131 & 23,7 \\
\hline INDUSTRIAL & 69 & 160 & 29,0 \\
\hline SUPERINTENDÊNCIA & 0 & 5 & 0,9 \\
\hline TOTAL & 296 & 552 & 100 \\
\hline
\end{tabular}

Fonte: Diretoria de Relações Industriais da Fiat; Setor de Desenvolvimento Organizacional (porcentagens referentes aos dados de 1998)

Duas análises podem ser realizadas, a partir dos dados anteriores:

- O crescimento do contingente dos engenheiros na empresa, logo uma ampliação do campo profissional para engenharia na empresa;

- Uma diversificação da atuação dos engenheiros, alocados em todas as áreas da fábrica.

Este levantamento quantitativo mostra, então, a ação extensiva e ampliada do engenheiro em toda a organização, principalmente com a porcentagem elevada de $23 \%$ (a segunda mais alta) na área comercial e, em compras: $14,1 \%$. Estes setores exigem do engenheiro uma atuação não mais limitada à realização técnica, mas uma qualificação diversificada a demandar conhecimentos de finanças, custos, economia, contabilidade, política de pessoal, entre outras do campo de gerência e de tomada de decisão administrativa.
O profissional oriundo do curso de engenharia de produção.

A pesquisa constou de duas etapas de entrevistas. $\mathrm{Na}$ segunda, dos sete engenheiros entrevistados, três eram engenheiros de produção. A investigação revelou que os engenheiros, com especialização em engenharia de produção, exercem mais facilmente as funções gerenciais da hierarquia da empresa. Possuem conhecimentos das ferramentas para a gestão dos processos produtivos e das mudanças organizativas, especialmente, dos planos de qualidade total, da reengenharia, como também do modelo japonês de produção - toyotismo. Além do saber técnico-científico necessário à realização industrial, podem intervir com maior propriedade nos conflitos das relações sociais no trabalho, quanto a harmonia dos procedimentos e atitudes do trabalhador.

Os engenheiros de produção entrevistados consideraram um grande diferencial a sua capacidade de intervenção nos modos organizacionais e gestionais da produção, em relação ao engenheiro do curso tradicional, que 
chega à empresa sem o domínio do desenvolvimento da produção. Portanto, os engenheiros de produção conseguem uma flexibilização funcional maior e integram-se mais facilmente em times nas diversas áreas da empresa. Possuem uma mobilidade mais acentuada com versatilidade para desempenho multifuncional e polivalente. Além do saber-técnico, como o engenheiro do curso tradicional, sem especialização em engenharia de produção, dominam os processos de organização do trabalho e da gerência produtiva. Logo, podem integrar-se ao setor produtivo com maior eficiência, além da flexibilidade na realização de diferentes empreendimentos seja na área industrial, comercial, financeira ou de gestão. Respondem mais rapidamente às demandas de trabalho, quando ingressam na empresa encurtando o período de adaptação no setor produtivo. Os seus conhecimentos nas relações homemmáquina e homem-homem são facilitadores para seu desempenho com eficácia na aplicação não só da técnica, mas das relações humanas em serviço e da organização dos processos produtivos.

\section{Principais atividades na construção da qualifica-} ção do engenheiro, em serviço

Nos depoimentos dos engenheiros entrevistados, ficou evidenciado que, apesar do Instituto Politécnico de Ensino Superior ter dado o start na construção da qualificação, é a Empresa o campo ideal para o seu desenvolvimento. Expressões usadas pelos engenheiros como $a$ Empresa é um curso de engenharia guardam um significado importante referente à aquisição da competência por meio do conhecer pela ação. A prática profissional, segundo os depoimentos dos engenheiros, é condição imprescindível à qualificação. A defasagem entre a escola e a empresa é real, não apenas pela impossibilidade da escola reproduzir em seus programas acadêmicos os eventos produtivos, como também porque não é função da Universidade oferecer padrões rotineiros de produção, mas municiar o engenheiro de capacidade de reflexão, análise e avaliação de processos, o que é traduzido na empresa pelas expressões ter respostas rápidas a curto prazo, ou ter partida automática, isto é, não esperar acontecer mas correr atrás. Aí está embutido o movimento dinâmico da qualificação, que privilegia mais a noção de fluxo e menos a de estoque. Saber trabalhar sob pressão implica a necessidade da formação de uma capacidade de resposta. $\mathrm{O}$ engenheiro na empresa é um solucionador de questões. A ele é dada a responsabilidade de gerir os processos, os quais pela sua dinâmica requerem capacidade de resposta rápida.

Inicialmente, esta capacidade é adquirida pelo engenheiro no relacionamento com o trabalhador que detém a prática, seja com seus pares ou com o pessoal da produção, em qualquer nível. A declaração de um engenheiro, levar a mesa da chefia para o chão de fábrica, expressa bem sua necessidade de convívio com os práticos. O saber técnico é adquirido na prática, no trabalho cooperado. A afirmação "o engenheiro tem que chegar e encostar no prático, e ele fala: esta máquina está com febre; e somente ele reconhece que a máquina está com avaria e necessita reparos", traduz a demanda pelo trabalho em equipe e mostra a importância da absorção do saber por meio do relacionamento horizontalizado, integrando teoria e prática.

Uma outra característica forte na composição da qualificação é a aquisição do conhecimento técnico pelo relacionamento com o fornecedor. Na fábrica globalizada, a prática da terceirização de serviços é norma. As firmas subcontratadas são escolhidas desde que possam prestar um serviço de qualidade. A questão é identificar como os benefícios são partilhados. A rede de firmas subcontratadas é fortemente especializada, tendo uma estrutura voltada para a prestação de serviços, pois deve atender às especificações emanadas da configuração dos produtos dimensionados pela empresa principal. Assim, seu grau de especialização é alto, visto que o atendimento às demandas da empresa principal exige mudanças contínuas, que podem significar uma alteração na estrutura do produto, de modo a incorporar inovações resultantes da competitividade do mercado. Neste sentido, mudar de empresa fornecedora é destruir um capital 
PRODUÇÃO

acumulado do saber-técnico e do saber-relacional. Em relação a essa questão, um engenheiro da produção fez o seguinte comentário:

$O$ relacionamento com o fornecedor é um convivio que pode ser muito conflituoso no início, mas em determinados momentos é qualificante. A responsabilidade da fabricação do produto não é da FIAT, mas do fornecedor, nas parcerias com atuação do co-design. É fundamental que os produtos cheguem à fábrica como especificado pela montadora.

Há um crescimento qualificacional do pessoal que atua na interação da fábrica principal e seus fornecedores, sobretudo do engenheiro como profissional responsável pela decisão dos links interfirmas e, em geral, líder dos grupos das empresas contratantes. A atividade de dimensionamento dos pedidos encaminhados às firmas fornecedoras passa pelo engenheiro, que ganha qualificação ao lidar com o trabalho especializado nessas firmas, as quais devem se adaptar rápida e eficazmente a toda mudança de encomenda da matriz, seja em relação a prazos, qualidade, especificações ou volume. Partindo do princípio de que a empresa fornecedora é moldada pela demanda da contratante, cabe ao engenheiro, como gerente do desenvolvimento do produto, e especialmente da engenharia do produto, tratar das especificações dos serviços.

A partir deste fazer-relacional, o engenheiro se envolve no tratamento das questões da produção e, assim, se atualiza ao tomar contato com inovações tecnológicas nos processos produtivos das subsidiárias e das diversas firmas prestadoras de serviços. Como as empresas fornecedoras se limitam à produção de componentes especificos, num restrito campo técnico, há sempre uma especialização de determinado ramo da tecnologia, pelo qual o engenheiro pode, então, ganhar capacitação e atualização. Comumente, na empresa principal, há uma fuga de toda produção especializada. Enfim, o fornecedor é, para os engenheiros da empresa principal, um agente de transfe- rência de conhecimentos e know how, em razão da bagagem acumulada através da interação com outras empresas, para as quais também presta serviço, o que facilita os intercâmbios tecnológicos.

Um outro tipo de relacionamento que deve ser considerado é aquele entre o setor de marketing e os fornecedores. De fato, é estratégico para a firma principal apresentar para as fornecedoras os resultados de pesquisas de mercado, seja em relação ao desenvolvimento de componentes pelas concorrentes seja em relação ao grau de satisfação do cliente quanto à performance do produto ou de suas partes. Isto é importante para otimizar a produção realizada pelos fornecedores.

Mais uma atividade que qualifica o engenheiro é sua interação com os dirigentes ou trabalhadores da matriz do conglomerado FIAT, na Itália, em qualquer nível. Inicialmente, a transferência de tecnologia se fez em trabalhos integrados na fábrica brasileira, pois quando da sua implantação, a gerência, até o nível intermediário, foi ocupada por técnicos vindos da matriz. Os primeiros modelos do produto foram trazidos praticamente prontos. A responsabilidade dos técnicos brasileiros se restringiu a gerenciar a produção. Com o desenvolvimento de novos produtos, os engenheiros brasileiros começaram a participar dos intercâmbios, demonstrando competência e facilidade para absorção tecnológica.

Um engenheiro do setor de desenvolvimento de produto assim se referiu a essa questão:

Antes havia uma divisão de responsabilidade e tarefas: parte na Itália e parte no Brasil. Essa divisão cresceu com a confiança pelos técnicos da matriz no trabalho dos engenheiros brasileiros, com atributos qualificacionais baseados na experiência originada na participação das equipes que trabalham nos modelos anteriores e até do motor a álcool produzido pelo Brasil. Há mudanças significativas nos carros originais para adaptação ao cliente brasileiro (suspensão diferente, motor com mais potência entre outras caracteristicas), o que pode ser considerado até um carro Fiat brasileiro. 
A partir de então, começaram a ocorrer visitas técnicas contínuas dos engenheiros brasileiros à matriz, para a realização de estágios. Estes intercâmbios têm o objetivo de trabalhar a adaptação regional do produto. Conforme o depoimento do gerente do setor de produto e da engenharia de produto,

A contribuição dos engenheiros brasileiros nas equipes de trabalho foi expressiva e culminou com sua integração aos grupos de estudo dos novos lançamentos da empresa, a nivel de um produto mundial.

Esses estágios e visitas, que em alguns setores ocorrem anualmente, vêm proporcionando condições de atualização e melhoria na capacidade técnica, organizativa e relacional dos engenheiros. A abrangência destas parcerias compreende praticamente todos os engenheiros. Os contatos pessoais existem, mas em muitos setores a troca de informações e discussão de questões acontecem via telefone, fax e outros meios de comunicação. Tais contatos ocorrem com freqüência, em muitos casos até diariamente.

Por ser a fábrica do Brasil uma filial de uma empresa estrangeira, os engenheiros foram induzidos a estudar o idioma dos técnicos da matriz para participar nos grupos interfuncionais, realizar as visitas técnicas à matriz e dirigir a fábrica junto com os técnicos estrangeiros. Assim, a maioria dos engenheiros na empresa domina pelo menos um idioma estrangeiro, que na maioria das vezes é o idioma do país de origem da matriz. Sem o domínio deste idioma, o engenheiro brasileiro perderia a oportunidade de capacitar-se via interação matriz-filial, o que dificultaria sua ascensão na hierarquia da empresa; conseqüentemente não teria promoção funcional. A versatilidade do engenheiro brasileiro ficou destacada como um atributo qualificacional fundamental para sua inserção nas equipes de desenvolvimento de produto na matriz.

$\mathrm{O}$ atendimento ao mercado e a necessidade de competitividade acarretam a demanda pela empresa da concepção de novos produtos. Na sua fabricação existem muitas etapas que constituem um campo fértil para o engenheiro se qualificar. A cada produto lançado são agregadas novas tecnologias e inovações, como a utilização de novos materiais (plástico, usado com muita freqüência), de performance diferencial em relação aos modelos das concorrentes (na aerodinâmica, por exemplo), além de comandos eletrônicos e mecanismos mais inteligentes. Segundo um engenheiro:

Hoje a Empresa trabalha muito na qualidade do produto, o foco é o produto. A centralização é na fabricação do produto, que não pode deixar de ser bem dimensionado tecnicamente, o que acontece na engenharia de produto.

Nesse momento, o engenheiro atua como analista ao realizar o breefing, método de trabalho voltado para a coordenação da execução de testes relativos à configuração e desempenho dos produtos similares no mercado. A realização do breefing se dá conjuntamente no Brasil e no país da matriz. Os dados levantados são tratados estatisticamente através da informatização dos sistemas computacionais e levados ao setor de marketing, ao setor de projetos e aos gestores de produto. Na aplicação desta metodologia, que visa garantir uma boa performance do produto da empresa em relação aos padrões do mercado e aos parâmetros tecnológicos em vigor, o engenheiro é responsável por todo levantamento e tratamento de dados, pela incorporação dos resultados na engenharia de produto e, posteriormente, na engenharia de produção ou de processos.

A qualificação do engenheiro se concretiza, nos atuais sistemas organizativos, quando ele se integra aos grupos interfuncionais, dos quais participam profissionais do produto, do processo e de qualidade do setor industrial, entre outros. Estes grupos facilitam o relacionamento e a tomada de decisão voltada para o processo como um todo, o que não acontecia anteriormente porque a decisão era tomada de modo parcial, sendo de responsabilidade de cada chefia. Decisões, agora, são de consenso, declararam os entrevistados. Essas mudanças do trabalho individualizado para o trabalho cooperado são causas do sucesso da 
PRODUÇÃO

Empresa no mercado, conforme afirmaram os engenheiros. Na redução da estrutura, a Empresa adotou medidas como as demais empresas, diminuindo os níveis hierárquicos até um patamar suportável, evitando a sobrecarga de tarefas. De acordo com um engenheiro-gerente:

O achatamento das estruturas levou ao crescimento da base e à obrigatoriedade de delegação de decisões, sem transferir a responsabilidade total.

O crescimento qualificacional dos engenheiros é significativo quando a Empresa muda seus padrões de organização e administração da produção, implantando o PQT e a Fábrica Racionalizada, cuja concepção e implantação são compartilhadas por consultores externos e pelo pessoal da própria Empresa. Cria-se, desse modo, um espaço para os técnicos, tecnólogos, supervisores e gerentes atuarem nos processos inovativos. Com esta abertura, há o envolvimento do pessoal de comando da Empresa na concepção dos novos sistemas de gestão; também há maior garantia de sucesso de sua aplicação, devido ao conhecimento e vivência das questões a serem tratadas, e possivelmente alteradas para melhor adequação dentro dos novos objetivos propostos. Em relação a esse aspecto, um engenheiro da diretoria de relações industriais fez a seguinte declaração:

$O$ engenheiro qualifica-se com a implantação de novos processos organizacionais como agentes multiplicadores e difusores das novas metodologias. Ao aprender ou repassar. Os cursos de engenharia de produção permitem uma maior aprendizagem das ferramentas do PQT. Os engenheiros oriundos de cursos com outras ênfases aprendem as tecnologias da qualidade na prática.

Desta forma, verifica-se um aperfeiçoamento qualificacional do pessoal envolvido, que recebe contribuição dos consultores e lideres das reestruturações. Pertencendo, às equipes que compõem as novas estruturas, o engenheiro evolui e consolida sua qualificação. Ao conhecer os parâmetros norteadores dos sistemas, pode, mais facilmente, alterar e aperfeiçoar os mecanismos em operação, e com isto evoluir na sua capacidade de tomar decisões com maior consistência e responder mais rapidamente às demandas dos processos produtivos.

\section{A escola como parceira da empresa na qualifica-} ção/requalificação profissional.

De um modo geral, na empresa pesquisada há um programa sistemático de treinamento de pessoal não só na área técnica mas, principalmente, para adaptações aos novos padrões de organização do trabalho. Em se tratando de pessoal de nível acadêmico superior, como os engenheiros, são desenvolvidas ações para capacitação e requalificação dos mesmos, em convênio com Universidades. Através do projeto denominado Educação e Cultura, dois programas da educação continuada resultantes de convênios Empresa/Escola, estão em oferta: um curso de pós-graduação Lato-Sensu, denominado Programa de Desenvolvimento Gerencial - PDG, visando ao aperfeiçoamento da atuação dos gerentes, quanto a sua performance de gestores da produção, um segundo programa é o Know How Engineer - KHE em convênio e parceria com várias universidades brasileiras, para atualização técnica do pessoal envolvido nos setores de processo e de fabricação.

Estas promoções da Empresa com parceria da Escola não se tratam, evidentemente de uma dádiva da Empresa, mas revela sua preocupação com o aumento da produtividade de seu Staff, através da melhoria da gestão dos processos. A Empresa tem uma dívida com seus profissionais dirigentes, que nestas duas últimas décadas dedicaram à sua consolidação e à sua evolução no mercado brasileiro sem disponibilidade e oportunidade para aperfeiçoamento profissional.

Há ainda a considerar o direcionamento da Empresa para o investimento na preparação de seu pessoal para assumir funções estratégicas e cargos na hierarquia. Assim, apesar de uma política ampla de atualização 
profissional, a Empresa é restritiva ao selecionar os candidatos aos programas de requalificação, especialmente, aqueles que certamente irão para o seu quadro de gerentes. Um dos engenheiros participantes do PDG explicou as condições de sua seleção para o referido programa em que os critérios de seleção privilegiam os engenheiros de alto potencial, futuros dirigentes.

Ao ser selecionado para o PDG estou sendo considerado pela Empresa como um profissional com potencial para estar no futuro quadro dirigente. Os critérios para a seleção ao PDG são: ser um profissional com potencial e ter dedicação ao trabalho, com possibilidade de dar retorno para a Empresa.

$\mathrm{O}$ investimento em recursos humanos pelas empresas não contempla apenas a qualificação do trabalhador para sua capacitação pessoal, mas a garantia de maisvalia relativa e a certeza de lucratividade crescente.

Evidentemente, a educação continuada não é realizada apenas pela Empresa, depende também da iniciativa do trabalhador, item pesquisado. Constatamos que há um investimento na qualificação dos engenheiros com graduação mais recente, especialmente, em informática e cursos de gestão, áreas de conhecimento demandadas atualmente pela administração moderna.

\section{5- Conclusões}

Assim, verificamos que a trajetória de construção da qualificação profissional passa pela formação acadêmica, pela ação no trabalho, sendo consolidada pelos programas da educação continuada. A requalificação do engenheiro se faz pelos novos processos da organização e gestão do trabalho, que trazem nos seus parâmetros conceptivos e operacionais exigências de competências que privilegiam, além do domínio técnico, habilidades e conhecimentos da administração de produção, habilidades comportamentais do trabalho cooperado e da interação originada pela descentralização produtiva da fábrica global.
Nossa investigação empírica mostrou como a empresa pesquisada, em conseqüência da sua integração ao sistema global da economia e da participação no complexo mundial de mercado, passou por várias reestruturações, não só por sua iniciativa, mas levada pela necessidade de se integrar ao modelo vigente de produção, pela procura de competitividade e qualidade, utilizando os mesmos padrões dos demais conglomerados produtivos.

Desse modo, a Empresa implementou sucessivos modelos organização contemplando metodologias e paradigmas comuns a todo sistema produtivo nacional e mundial, tendo em vista que o isolamento acarreta perda de competitividade pelo desconhecimento e tratamento inadequado da informação, moeda atual da economia.

De uma maneira geral, a escola encarrega-se do processo de formação profissional em primeiro nível; contudo, não tem uma ênfase essencial e exclusivamente acadêmica. A escola busca compor seus programas com base em cenários prospectivos de atuação e perfil profissional do engenheiro. É a empresa, com seus parâmetros peculiares, que influencia e assessora a escola para a definição de seus objetivos.

Em um segundo momento, é a atuação profissional que tem uma dimensão qualificacional, essencial à composição da capacitação do engenheiro. Na prática do trabalho, na aplicação concreta de suas capacidades intelectuais, pelo conhecimento adquirido e acumulado, e ainda na utilização das habilidades atitudinais ou comportamentais, o profissional realimenta a dinâmica do crescimento qualificacional. A cada projeto concebido e desenvolvido, a cada produção concretizada, o engenheiro desenvolve suas capacidades e assiste ao aperfeiçoamento de suas potencialidades. Nesta segunda fase, da essência e da excelência do processo qualificacional, o engenheiro não está só, pois o desempenho da profissão se faz nas relações de trabalho, ao participar dos times, ao compor os grupos de trabalho junto ao fornecedor ou ao cliente, ao mudar de posição com a flexibilização funcional e mudanças estruturais, ou de cargos, na supervisão ou chefia de diversos serviços. 
Mostramos que a qualificação do engenheiro é construída em serviço, embora tenha seu alicerce na graduação da escola de engenharia, sendo complementada e sistematizada pelos programas da educação continuada terceira etapa da trajetória qualificacional. Nesse momento, empresa e escola se associam, firmando convênios que garantam a extensão universitária, constituída de projetos de pesquisa, consorciados ou da prestação de serviços, permitindo planejar e operacionalizar as ações de requalificação. A programação que compõe a

requalificação é informal, de modo a atender às necessidades surgidas das problematizações da ação concreta do trabalho, efetivada a cada momento da produção.

Em suma, a integração é a essência do binômio qualificação/requalificação, que desconhece fronteiras da formação, da atuação ou do refazer qualificacional. Se novas profissões e espaços são criados para atuação diversificada do engenheiro, não há como delimitar seu campo de trabalho. Os saberes especializados envelhecem rapidamente. A velocidade das mudanças da tecnologia, dos sistemas organizacionais e de gestão demandam um profissional qualificado, formado em uma escola preocupada não com uma educação terminal, mas com uma educação permanente.

A escola com sua pedagogia, seus métodos formais e sistematizados é parceira da empresa na construção qualificacional do trabalhador, pois nos novos processos produtivos os conhecimentos passam a ter valor de força produtiva. A escola, com sua missão de sistematizar o saber, coopera no mundo do trabalho para o planejamento, controle e regulamentação da educação, que acontece pela ação na realização profissional e nos programas da educação continuada. Ademais, a escola leva para a empresa a sua cultura pedagógica, analítica e questionadora, assegurando a continuidade e o crescimento qualificacional da força de trabalho nas articulações, contradições e tensões dos sistemas produtivos.

O cotidiano da Universidade, pautado na conservação, aprofundamento, acumulação e, sobretudo, socialização do conhecimento, tem também a função de renovação, criação e ruptura epistemológica. Conservar o passado, construir o novo com base na crítica permanente: esta é a missão da Universidade, a ser realizada em sistema cooperativo com a empresa. Esta, pela sua natureza, preocupada com a produção e o mercado, é assessorada pela escola, cujo saber é articulado, sistematizado e organizado, ancorado na crítica, na reflexão e na pluralidade conceitual e metodológica dos conhecimentos técnicos, culturais e sociais.

Assim, a escola é chamada pela sociedade contemporânea a se associar ao setor produtivo na formação de recursos humanos, visto que o processo de qualificação/ requalificação tem, nas relações de trabalho, uma natureza contínua e permanente de construção do saber socializado e relacional, no trabalho cooperado da rede da fábrica globalizada, o que exige uma abordagem pedagógica da ação no trabalho, característica do fazer acadêmico.

Finalmente, a formação e a qualificação profissional do engenheiro não mais se restringem ao curso de graduação para uma capacitação essencialmente técnica. A fábrica global está a exigir um profissional com atuação flexível e ampliada no campo das relações sociais de trabalho além do desempenho técnico, com capacidade de atualização qualificacional. Os atributos do aprender a aprender, da capacidade de transferência do conhecimento, da busca de informação, do tratamento de dados caracterizam o profissional, especialmente o de nível superior, na tomada de decisão à frente dos processos de gestão da produção.

É um desafio para o trabalhador identificar espaços para sua formação e qualificação na promoção pela Empresa dos programas de capacitação profissional na busca do crescimento da produtividade do trabalho e da competitividade concorrencial interempresas. 


\section{6- Referências Bibliográficas}

BRAVERMAN, Harry. Trabalho e capital monopolista. A degradação do trabalho no século XX. Rio de Janeiro: Guanabara, 1987. 379 p.

BRUNO, Lúcia .Educação, qualificação e desenvolvimento econômico. In: BRUNO, Lúcia(org.). Educação e trabalho no capitalismo contemporâneo. São Paulo: Atlas. 1996. pp.91 - 113.

CASTILLO, Juan J.. Diseño del trabajo y cualificación de los trabajadores en una fabrica de motores. In: Madrid. Ministerio del Trabajo y Seguridad Social. Espanha. 1991. pp. 261-336.

CORIAT, Benjamin.. Pensar pelo avesso: o modelo japonês de trabalho e organização. Rio de Janeiro: Revan, UFRJ. 1994. 209 p.

CORIAT, Benjamin. EL Taller y el Robot: Ensayos sobre el fordismo y la producción en masa en la era electronica. Madri: Siglo Veintiuno de espana editores, s.a. 1992.266 p.

COUTINHO, Luciano.. A terceira revolução industrial e tecnológica: As grandes tendências de mudanças. São Paulo: Economia e Sociedade, no 1, Agosto/ 921992 pp. 69-87.

DELUIZ, Neise..Formação do trabalhador: produtividade e cidadania. Rio de Janeiro: Shape. 1995212 p.

FLEURY, Afonso C.C. Novas Tecnologias, capacitação tecnológica e processo de trabalho: Comparações entre o Modelo Japonês e o Brasileiro. In: HIRATA, H. S. (org.) Sobre o Modelo Japonês. São Paulo:

Edusp.1993. 33 - 47 pp.

HARVEY, David. Condição pós-moderna - Uma pesquisa sobre as origens da mudança cultural. São Paulo: Edições Loyola. 1994. 349 p.
KAWAMURA, Lili Katsuco. Engenheiro; trabalho e ideologia. São Paulo: Ática. 1981. 130 p.

KUENZER, Acácia Zeneida. Pedagogia da fábrica. As relações de produção e a educação do trabalhador. São Paulo: Cortez. 1995. 205 p.

LAUDARES, João Bosco. A requalificação do engenheiro do setor metal - mecânico: uma necessidade dos novos processos de trabalho. Tese de doutoramento. PUC/SP. 1998. 216 p.

LEITE, Elenice Monteiro. O resgate da qualificação. Tese de doutoramento. Faculdade de Filosofia e Letras e Ciências Humanas da Universidade de São Paulo - USP. 1994.255 p.

MACHADO, Lucília Regina de Souza. Mudança na ciência e na tecnologia e a formação geral em face da democratização da escola. In: MARKET, Werner(org.). Trabalho, qualificação e politécnica. Campinas, São Paulo: Papirus. 1996. pp.131-145.

MARKET, Werner. (org.). Trabalho, qualificação e politecnia. São Paulo: Papirus. 1996. 160 p.

PAIVA, Vanilda. Produção e qualificação para o trabalho: uma revisão da bibliografia internacional. Ensino das humanidades. São Paulo: Cortez, Cadernos SENEB. 1991. pp. 19 - 103.

QUADROS, Carvalho Ruy, SCHMITZ, Hubert. O fordismo está vivo no Brasil. S. Paulo: Novos Estudos, CEBRAP, no 27, Julho. 1990. pp.148 - 156.

SALERNO, Mário. S. Trabalho e organização na empresa integrada e flexível. São Paulo: Trabalho apresentado no seminário multidisciplinar sobre trabalho e educação. Fundação Carlos Chagas. 1992. 
PRODUÇÃO =

SALERNO, Mário. S. Modelo japonês, trabalho brasileiro. In: HIRATA, H. S. (org.) Sobre o Modelo Japonês. São Paulo: EDUSP. 1993. pp. 139 - 152.

TANGUY, Lucy, ROPÉ, Françoise. Savoirs et compétences. De l'usage de ces notion dans l' école et l'entreprise. Paris - França: Editions L'harmattan. 1994. $243 \mathrm{p}$.

VILLAVICENCIO, D. Por una definición de la cualificación de trabajadores. Trabalho apresentado no IV Congresso Espanhol de Sociologia. Madrid, Espana. 1992. 